\title{
ГРИБ GANODERMALUCIDUM KAK ПЕРСПЕКТИВНЫЙ ПРОДУЦЕНТ БИОЛОГИЧЕСКИ АКТИВНЫХ ВЕЩЕСТВ
}

\section{GANODERMA LUCIDUM AS A PERSPECTIVE PRODUCER OF BIOLOGICALLY ACTIVE SUBSTANCES}

S. Garayeva

Summary. The xylomycobiota of the forests located in the Greater Caucasus of the Republic of Azerbaijan was assessment by the species composition, ecological-trophic relations, distribution on the individual tree species and as a potential producer of BAM. As a result of researches carried in the forests were found 51 species of fungi, of which $84.3 \%$ cause white, $15.7 \%$ brown rot, and $5.9 \%$ are attributed to true biotrophs, $3.9 \%$ - to true saprotrophs, $90,2 \%$ - to polytrophs. It was found that among the recorded fungi are also found species with high growth rates in the vegetative phase, and among the metabolites synthesized by them take part those which have biological activity. Firstly were determined that metabolites synthesized by mushrooms are perspective to use in food, feed and medical purposes.

Keywords: forest ecosystems, xylotrophic macromycetes, ecolo-trophic relations, vegetative phase, biological activity.

\author{
Караева Севиндж Джамаледдин кызы \\ М.н.с., Институт микробиологии НАНА, г. Баку \\ azmbi@mail.ru
}

Аннотация. Проведена оценка ксиломикобиоты лесов, расположенных на Большом Кавказе Азербайджанской Республики, на предмет её видового состава, экологических и трофических связей, распределения по отдельным видам деревьев и потенциала как продуцента БАВ. В результате в исследованных лесах был обнаружен 51 вид грибов, из которых 84,3\% вызывают белую, 15,7\% -бурую гнили, 5,9\% отнесены к истинным биотрофам, 3,9\% — к истинным сапротрофам, а 90, 2\% -к политрофам. Было установлено, что среди грибов, распространение которых было зарегистрировано, встречаются также виды с высокой скоростъю роста в вегетативной фазе, а некоторые синтезируемые ими метаболиты проявляют биологическую активность. Метаболиты, синтезируемые грибами рода Ganoderma, были первоначально определены как перспективные для использования в кормовых, пищевых, медицинских целях.

Ключевые слова: лесные зкосистемы, ксилотрофные макромицеты, эколо-трофическая связь, вегетативная фаза, биологическая активность.
B соответствии с темпами современного развития усиливается вмешательство человека в природу и природные ресурсы. В результате большинство природных ценозов превращаются в антропогенно-трансформированные антропогенные ценозы. Результат этой трансформации проявляется в болезнях, катаклизмах и других неприятных явлениях, и эта тенденция развивается по восходящей линии. Предотвращение этого, устранение негативных последствий антропогенного воздействия на окружающую среду, обеспечение здоровья человека в соответствии с меняющимися требованиями современного мира является одной из интересующих и волнующих всех сегодня задач [11]. По этой причине в течение длительного времени в направлении решения этих проблем проводятся обширные исследования, делаются попытки оздоровления экологической обстановки окружающей среды, укрепления иммунной системы человека, одним словом, ведется поиск средств, позволяющих устранить негативные последствия антропогенного воздействия. Исследования в этой области, особенно связанные со здоровьем человека, сосредоточены на биологически, в том числе, фармакологически активных веществах, укрепляющих иммунную систему. Не случайно интерес к разработке лекарственных средств на основе природных источников растет день ото дня, а изучение природных источников лекарственных средств становится особой областью исследований $[4,8]$.

В классическом смысле продуценты биологически активных веществ (БАВ), полученные из биологических систем и характеризующиеся как органические вещества, которые в небольших количествах оказывают существенное влияние на биологические процессы в живых организмах, включают виды, принадлежащие ко всем таксономическим группам клеточных организмов[12]. Так, среди продуцентов БАВ, которые в настоящее время используются для разных целей в разных областях, есть виды, относящиеся к бактериям, грибам, растениям и животным.

Грибы, составляющие 5-6\% от известных на сегодняшний день науке примерно 2-х миллионов живых существ на Земле[13], привлекают внимание как продуценты биологически активных веществ и в качестве естественных источников являются одними из самых исследуемых в последнее время живых организмов. Так, наличие у них широкого спектра экологических функ- 
ций в природе, высокой скорости роста в вегетативной фазе, способности синтезировать БАМ, отличающейся широтой как эффекта воздействия, так и ассортимента, высокой возможности использования сложных растительных остатков при культивировании и т.д. повышает интерес к ним.

Грибы, различаясь по многим особенностям не только между собой, но и от других живых существ, характеризуются также разнообразием таксономических и экологических аспектов [1, 10], а ксилотрофы, выделяемые как экологическая группировка, находятся в центре внимания [15]. Таким образом, ввиду того, что ксилотрофные грибы находятся в центре внимания последних исследований и в настоящее время широко изучаются в мировой практике как продуценты БАВ [16-19] и на их основе создан процесс производства, их удельный вес среди грибов продолжает расти. Schyzophyllium commune, Ganoderma lucidum, Inonotus obligus, Lentinis edodes, Pleurotus ostreatus и другие ксилотрофные грибы в настоящее время относятся к числу грибов, используемых как в фундаментальных научных исследованиях, так и для практических целей в промышленных масштабах. Плодовые тела, образованные ксилотрофными грибами в естественных условиях, в основном, широко распространены в лесных экосистемах, и проведенные исследования показывают, что на показатели, характеризующие их как продуценты БАВ, влияют также экологические условия их распространения. Это позволяет отметить, что поиск целевого продукта в конкретной экосистеме, т.е. штаммов характеризующихся более активными, по крайней мере, более высокими количественными показателями БАВ различного назначения, все еще сохраняет свою актуальность. По этой причине продолжаются работы в этом направлении.

Ксилотрофные макромицеты наиболее широко распространены в лесных экосистемах и, несмотря на меньшую степень распространения на территории Азербайджанской Республики, здесь также обнаруживаются ксилотрофные макромицеты, и в проведенных до настоящего времени исследованиях выявлено 212 видов этих грибов [9]. Хотя и можно указать конкретную цифру количества видов ксилотрофных макромицетов для Азербайджана, но невозможно привести конкретную цифру их числа в мире и в лучшем случае эта цифра предположительно не превышает 2000 видов.

Число видов ксилотрофных макромицетов как продуцентов БАВ, изученных в мире, в том числе на территории Азербайджанской Республики, составляет небольшую часть видов, известных сегодня науке. Интересно, что грибы, изучаемые во многих мировых научных центрах, являются штаммами одного и того же вида. Одним словом, небольшое количество видов ксилотрофных ма- кромицетов стали предметом исследования, и это число нельзя считать достаточным для оценки потенциала, присущего ксилотрофным макромицетам в целом.

По этой причине представленная работа посвящена характеристике видового состава ксиломикобиоты лесов территории Азербайджанской Республики, созданию коллекции культур, состоящей из быстрорастущих чистых культур и первоначальной оценке их потенциала как продуцентов БАВ.

\section{материалы и метомы}

11,8\% территории Азербайджанской Республики покрыто лесами, из которых 49\% расположены на Большом Кавказе, 15\% в Талышских горах, 34\% на Малом Кавказе и 2\% в Кура-Аразской низменности [14]. Учитывая, что большая часть лесов расположена на Большом Кавказе, целесообразно было провести исследования именно здесь.

Отбор проб для исследования проводился в соответствии с маршрутным методом. Ширина маршрутасоставила5-6 м, а длина - 100-2000 м. Были зарегистрированы все плодовые тела (ПТ) ксилотрофных макромицетов, встречающихся на растущих вдоль маршрута деревьях. При определении частоты встречаемости считалось целесообразным регистрировать на одном дереве 1 ПТ одного вида гриба независимо от их количества. При расчете приблизительного количества ПТ, образуемого грибами в течение года, учитывались все плодовые тела.

Информация, необходимая для характеристики ПТ (участок, первоначальное морфологическое описание, субстрата, биологического состояния субстрата и т. д), указывалась на месте и помещалась в бумажные конверты. Последующий анализ ПТ проводился в лаборатории, использовался также метод микроскопического исследования.

Идентификация грибов проводилась на основе морфологического описания ПТ и данных, полученных в ходе лабораторного анализа (форма базидий, форма и размер базидиспор, структура и размер гименофора, гифальная система) и использовались известные определители $[2,7]$.

Для получения чистой культуры использовались ПТ, образуемые грибами в естественных условиях[6]. Для этого от слегка очищенной спиртом гименофорной части ПТ, взятого в естественных условиях, отрезают кусок и переносят в питательную среду (2-30В агаризованное сусло -АС), инкубируют в термостате при 280 С. Начиная с 3-го дня инкубации из развившегося на питательной среде материала берется визуально гомогенная часть 
Таблица 1. Общая характеристика таксономической принадлежности и распределения по субстратам зарегистрированных в ходе исследования ксилотрофных макромицетов отдела Bazidiomycota

\begin{tabular}{|c|c|c|c|}
\hline Класс & Порядок & Семейство & Род и вид \\
\hline \multirow{12}{*}{$\begin{array}{l}\text { Agarico- } \\
\text { mycetes }\end{array}$} & \multirow{5}{*}{ Polypo-rales } & Polyporaceae & $\begin{array}{l}\text { Cerrena unicolor, Fomes fomentarius, Fomitopsis annosa, F.cytisina, } \\
\text { F.officinalis, F.pinicola, F.rosea, Hirschioporus pargamenus, Lentinus } \\
\text { strigosus, Lenzites betulina, Polyporus squamosus, P.vaporarius, P.varius, } \\
\text { Pycnoporus cinnabarinus, Trametes heteromorpha, T.hirsitum, T.ochracea, } \\
\text { T.pubescens, T.versicolor, T.zonata, Tyromyces amorphous }\end{array}$ \\
\hline & & Meruliaceae & Bjerkandera adusta, Heteroporus biennis, Rigidoporus ulmarius \\
\hline & & Fomitopsidaceae & Daedalea quersina, Laetiporus sulphureus \\
\hline & & Ganodermataceae & Ganoderma applanatum, G.lucidum, G.resinaseum \\
\hline & & Phanerochaetaceae & Abortoporusbiennis, Hyphodermasetigerum \\
\hline & $\begin{array}{l}\text { Hymeno- } \\
\text { chaetales }\end{array}$ & Hymenochaetaceae & $\begin{array}{l}\text { Inonotus cuticularis, I.hispidus, I.pini, I.radiatus, Phellinus contiguus, } \\
\text { Ph.gilvus, Ph. Igniarius, Ph.pini, Ph.pomaceus, Ph.robustus, Ph.tremulae }\end{array}$ \\
\hline & \multirow{4}{*}{ Agari-cales } & Pleurotaceae & Pleurotus cornucopiae, P.ostreatus \\
\hline & & Schizophyllaceae & Schizophyllum commune \\
\hline & & Physalacriaceae & Armilariamellea, Flammulina velutipes \\
\hline & & Pluteaceae & Pluteus leoninus \\
\hline & \multirow{2}{*}{ Russu-lales } & Stereaceae & Stereum gausapatum, S.hirsutum \\
\hline & & Peniophoraceae & Peniophora gigantea \\
\hline
\end{tabular}

и переносится в новую питательную среду, и этот процесс продолжается до тех пор пока не будет получена чистая культура определенного вида. Чистота полученной культуры контролируется с помощью микроскопа (OMAX 40X-2500X LED Digital Lab Trinocular Compound Microscope).

При характеристике грибов, выведенных в чистую культуру, по скорости роста, было сочтено целесообразным охарактеризовать эти грибы в соответствии со скоростью роста на АС, и с этой целью использовали коэфициент роста (КР), указанный в работе А.С. Бухало[3].

Оценка выделенных чистых культур с высокими скоростями роста как продуцентов БАВ проводилась в условиях жидкофазной ферментации (ЖФ), для которой использовались их культуральные жидкости (КЖ). КЖ получают путем отделения биомассы, образованной конкретным грибом, после 5 дней глубинного культивирования в жидкой глюкозо-пептонной среде. Присутствие биологически активных метаболитов в КЖ грибов оценивали по способности прорастания семян некоторых растений. Выяснение этого вопроса проводилось в соответствии с подходом, использованным в работе К.Ф. Бахшалиевой [1].

В ходе исследования все эксперименты были выполнены не менее чем в 4-х повторениях, а результаты были статистически обработаны [5].

\section{Результаты и их обсужАения}

В результате исследований, проведенных в лесах Большого Кавказа Азербайджанской Республики за 2015-2018 гг., был изучен видовой состав ксилотрофных макромицетов и частота их встречаемости на разных породах деревьев. Полученные результаты показали, что в формировании ксиломикобиоты изученных лесов участвует 51 вид грибов, количественно обобщенная информация о которых приведена в таблице 1.

Как видно ксиломикобиота лесов, состоящая из таких основных лесообразующих пород как граб обыкновенный, бук восточный, липа обыкновенная и дуб каштанолистный, представлена 1 видом уодних родов (Bjerkandera, Cerrena, Fomes, Heteroporus, Peniophora, Rigidoporus, Schizophyllumи др.), 2-4 видами у других (Ganoderma, Inonotus, Pleurotus, Polyporus и Stereum) и 7 видами у родов Phellinus и Trametes соответственно.

Зарегистрированные грибы характеризуются различиями не только в количестве видов, формирующих ксиломикобиоту, но и других показателей. Так, среди зарегистрированных грибов встречаются виды, вызывающие в естественных условиях как белую, так и бурую гниль. Например, Bjerkandera adusta, Cerrena unicolar, Fomes fomentarius, Ganoderma applanatum, G.lucidum, Phellinus igniarus и др.вызвают гниль бело- 
Таблица 2. Влияние на прорастание семян огурца и нарост Tetrahymena pyriformis ВМ и КЖ грибных штаммов, отобранных как активные продуценты

\begin{tabular}{|c|c|c|c|c|c|c|c|c|c|c|c|c|c|}
\hline \multirow{3}{*}{ № } & \multirow{3}{*}{$\begin{array}{l}\text { Активные } \\
\text { продуценты }\end{array}$} & \multicolumn{6}{|c|}{ Влияние на прорастание семян огурца } & \multicolumn{6}{|c|}{ Влияние нарост Tetrahymena pyriformis } \\
\hline & & \multicolumn{2}{|c|}{$\begin{array}{l}\text { Общее } \\
\text { количество } \\
\text { семян } \\
\end{array}$} & \multicolumn{2}{|c|}{$\begin{array}{l}\text { Число } \\
\text { проросших } \\
\text { семян } \\
\end{array}$} & \multicolumn{2}{|c|}{$\begin{array}{l}\text { Снижение } \\
\text { Прорастания } \\
\text { (\%) } \\
\end{array}$} & \multicolumn{2}{|c|}{$\begin{array}{l}\text { Исходное } \\
\text { число клеток }\end{array}$} & \multicolumn{2}{|c|}{\begin{tabular}{|l} 
Конечное \\
число клеток \\
(через 1день) \\
\end{tabular}} & \multicolumn{2}{|c|}{$\begin{array}{l}\text { Эффект } \\
\text { роста } \\
\text { (разы) } \\
\end{array}$} \\
\hline & & BM & Kж & BM & K\% & BM & Kж & BM & Kж & BM & KK & BM & Kж \\
\hline 1 & G.aplanatum S-7 & 350 & 350 & 302 & 315 & 13,8 & 10,0 & 140 & 142 & 138 & 184 & $-1,04$ & 1,30 \\
\hline 2 & G.lucidum S-12 & 350 & 350 & 320 & 328 & 8,6 & 6,3 & 152 & 150 & 248 & 295 & 1,63 & 1,97 \\
\hline 3 & G.resinaceum S-16 & 350 & 350 & 300 & 311 & 14,3 & 11,2 & 134 & 141 & 140 & 178 & 1,04 & 1,27 \\
\hline 4 & Контроль & \multicolumn{2}{|l|}{350} & \multicolumn{2}{|l|}{310} & \multicolumn{2}{|l|}{11,4} & \multicolumn{2}{|l|}{143} & \multicolumn{2}{|l|}{176} & \multicolumn{2}{|l|}{1,23} \\
\hline
\end{tabular}

ro, a Fomitopsis pinicola, Inonotus hispidus, Laetiporus sulphureus, Rigidoporus ulmarius и др. вызвают гниль бурого цвета. В целом, 84,3\% зарегистрированных грибоввызывают в естественных условияхбелую гниль, а 15,7\% - бурую гниль.

Отличительными признаками зарегистрированных грибов являются их распределение по субстратам, эколого-трофические отношения (5,9\% - истинные биотрофы, 3,9\% - истинные сапротрофы, 90,2\% -политрофы), а также гифальные системы (мономитические, димитические и тримитические) и количество волн формирования плодового тела в естественных условиях (один или два раза в год, многократно). Таким образом, ксиломикобиота лесов Азербайджана на Большом Кавказе состоит из видов, характеризующихся широким разнообразием в различных аспектах.

Как известно, грибы, в первую очередь ксилотрофные макромицеты, привлекают внимание как продуценты БАВ, и с этой целью объектом исследования становятся как образуемые ими в естественных условиях плодовые тела (ПТ), так и мицелий в фазе вегетативного роста. Многочисленные исследования показали, что для этих целей целесообразно использовать обе субстанции грибов. Ввиду ограниченных ресурсов ПТ, продуцируемых грибами в естественных условиях, использование мицелия в фазе вегетативного роста считается более перспективным. Поэтому, на следующем этапе исследования были выяснены вопросы, связанные с поиском активных продуцентов среди чистых культур, выделенных из ПТ зарегистрированных грибов. Исследования, проводимые на этом этапе, велись в два этапа, первый из которых был связан с оценкой грибных культур на образование биомассы в жидкой питательной среде.

Было бы целесообразно затронуть еще одну проблему, связанную с исследованиями, проводимыми на данном этапе. В ходе исследования из зарегистрированных 51 вида грибов в чистую культуру было выделено 117 штаммов. Из них 17 штаммов принадлежали роду
Ganoderma, и в ходе последующих исследований как продуценты БАМ были всесторонне изучены штаммы, принадлежащие именно этому роду. Для выбора активного штамма был проведен первоначальный отбор, и в данном случае был сделан отбор 1 активного штамма из 3 видов, принадлежащих роду Ganoderma. В результате исследования было выявлено, что штаммы грибов рода Ganoderma имеют различия в количестве биомассы, которую они образовали в одинаковой питательной среде, и в этом случае разница между самой активной и самой слабой культурой составила 3,4 раза. Однако такие штаммы, как $G$. aplanatum $S-7, G$. lucidum $S-12$ и $G$. resinaceum $S$-16, были отобраны для следующего этапа исследований, и количество биомассы, которую они продуцировали в жидкой питательной среде, составило 6,7 г/л, 7,7 г/л и 6,1 г/л соответственно.

На следующем этапе отобранные штаммы были оптимизированы по основным параметрам питательной среды (химический состав источников азота и углерода и их количество, добавляемое в среду, начальный рН среды, температура культивирования, способ приготовления и срок посевного материала). В результате выход биомассы увеличился на 8-12\% по сравнению с образуемой на исходной питательной среде. На оптимальной среде было определено наличие токсической активности биомассы, то есть вегетативного мицелия (ВМ) и культуральной жидкости (КЖ). Для этого использовались как инфузория (Tetrahymena pyriformis), так и семена огурца. Результаты показали различие метаболитов культуральной жидкости (КЖ) и вегетативного мицелия (ВМ) всех грибов (таблица 2). Как видно, метаболиты гриба G.lucidum $S-12$, имеющиеся как в ВМ, так и в КЖ не обладают токсическим действием и в обоих случаях оказывают стимулирующее действие. В действии других грибов наблюдается как усиление прорастания, так и замедление прорастания семян, и во всех случаях стимулирующий эффект не выше, чем при использовании гриба G.lucidum. Аналогичная ситуация наблюдается при использовании спиртового экстракта ВМ, а также КЖ грибов. 
Следует особо отметить результаты, которые связаны с действием КМ и ВМ грибов. Как видно, во всех случаях при использовании КЖ наблюдается, хотя и незначительный, эффект усиления, но в отношении ВМ это проявляется не всегда. Это позволяет отметить экзогенную природу синтеза метаболитов, вызывающих стимулирующий эффект.

Таким образом, в ходе проведенных исследований было выявлено, что как ВМ, так и КЖ грибов Ganoderma, распространенных в Азербайджане, содержат биологически активные метаболиты, которые включают метаболиты, оказывающие как стимулирующее, так и подавляющее действие. Тот факт, что КЖвсех исследованных грибов содержат метаболиты, обладающие стимулирующим эффектом, и это в большей степени обнаруживаются у гриба G.lucidum $S$-12, а также аналогичное действие его ВМ, указывает на перспективность данного гриба при использованиив будущем в качестве продуцента БАВ.

\section{ЛИТЕРАТУРА}

1. Бахшалиева К. Ф. Экобиологические особенности токсигенных грибов, распространенных в Азербайджане. Автореферат дисс.д.б.н. Баку, 2017, 45с.

2. Бондарцева, М. А. Определитель грибов России. Порядок афиллофоровые. СП.: Наука, 1998, вып. 2, 391с

3. Бухало А.С. Высшие съедобные базидиомицеты в. чистой культуре. Киев: Наукова думка, 1988, 144c.

4. Жилинская Н. В. Противомикробные свойства базидиомицетов Fomitopsis officinalis (Vill.: Fr.) Bond. et Sing., Fomitopsis pinicola (Sw.: Fr) P. Karst. и Trametes versicolor (L.: Fr.) Lloyd: оценка перспектив использования в технологии пищевых продуктов. Диссертация ...... к. б.н. Москва, 2015, 195с.

5. Кобзарь А. И. Прикладная математическая статистика. М.: ФИЗМАТЛИТ, 2006, 816 с.

6. Методы экспериментальной микологии/Под. ред. Билай В. И. Киев: Наукова думка, 1982, 500с.

7. Мухин В. А. Полевой определитель трутовых грибов. Екатеринбург, 1997, 104 с.

8. Толстикова Т. Г., Толстиков А. Г., Толстиков Г. А. Лекарства из растительных веществ. Рос. акад. наук, Сиб. отд-ние, Новосиб. ин-т орган, химии им. Н. Н. Ворожцова.-Новосибирск: Академическое изд-во «Гео», 2010, 215 с.

9. Akhundova N. A., Orucova S. B., Bahshaliyeva K. F., Muradov P.Z. and Rahimov E. A. Evaluation by the Oxidase Activity of Xylotropic Macromycetes Causing White Decay.// Advances in Bioscience and Biotechnology, 2019, v.10, p.179-187.

10. Alves M. J., Ferreira I. C., Dias J. et. al. A review on antimicrobial activity of mushroom (Basidiomycetes) extracts and isolated compounds// Planta Med., 2012, v. 78, № 16, p.1707-1718.

11. Cleland J. World Population Growth; Past, Present and Future.// Environmental and Resource Economics, 2013, v.55(4), p.543-554.

12. Grigorova S., Abadjieva D. and Gjorgovska N. Influence of Natural Sources of Biologically Active Substances on Livestock and Poultry Reproduction// Iranian Journal of Applied Animal Science, 2017, v.7(2), p.189-195

13. Hawksworth D. L., Lücking R. Fungal diversity revisited:2.2 to 3.8 million species.//Microbiol Spectrum, 2017, v.5(4), p.1-11

14. http://eco.gov.az

15. Osinska-Jaroszuk M., Jarosz-Wilkołazka A., Jaroszuk-Sciseł J., Szałapata K.et al. Extracellular polysaccharides from Ascomycota and Basidiomycota: production conditions, biochemical characteristics, and biological properties.// World J Microbiol Biotechnol., 2015, 31:1823-1844

16. Rana N., Vaidya D., Sharma S. and Chauhan N. Chemical profile and amino acids composition of edible mushroom.// International Journal of Agriculture, Environment and Biotechnology, 2015, v.8(3), p.675-679

17. Ruthes A. C., Smiderle F. R., lacomini M. Mushroom heteropolysaccharides: A review on their sources, structure and biological effects.// Carbohydr. Polym., 2016, v.136, p.358-375.

18. Su C.H., Lai M.N., Lin C.C., Ng L.T. Comparative characterization of physicochemical properties and bioactivities of polysaccharides from selected medicinal mushrooms.// Appl. Microbiol. Biotechnol., 2016, v. 100, p.4385-4393

19. Wang Q., Wang F., Xu Z., and Ding Z. Bioactive Mushroom Polysaccharides: A Review on Monosaccharide Composition, Biosynthesis and Regulation.// Molecules, 2017, v.22, is.6, p.955-967 